\title{
The Effects of Sugammadex On Coagulation In
}

\section{Pregnant Rats}

\author{
Mehmet Emin Keskin ${ }^{1 *}$, Havva Sayhan Kaplan ${ }^{2}$, Nurçin Gülhas ${ }^{3}$, Yasemin Bayram ${ }^{4}$, Yildiray \\ Basbugan $^{5}$ \\ ${ }^{1}$ Depertmant of Anesthesiology and Reanimation, Van Education and Research Hospital, University of Health Sciences, \\ Van, Turkey \\ ${ }^{2}$ Department of Anaesthesiology and Reanimation, Yuzuncu Yil University, Van, Turkey \\ ${ }^{3}$ Department of Anaesthesiology and Reanimation, Inonu University, Malatya, Turkey \\ ${ }^{4}$ Department of Medical Microbiology, Yuzuncu Yil University, Van Turkey \\ ${ }^{5}$ Department of Veterinary Medicine, Yuzuncu Yil University, Van, Turkey
}

\begin{abstract}
Some studies have reported that sugammadex affects coagulation parameters. However, the effects of sugammadex on coagulation in pregnant women have not been adequately evaluated. This study investigated the effects of sugammadex administration on routine coagulation tests and levels of coagulation factors (FII, FV, FVII, FVIII, FIX, and FX) in pregnant rats.

After ethics committee approval (2019/06), 24 female Wistar albino rats ( $\mathrm{n}=12 ; 19-20$ days of gestation; weight 230-380 g) were randomly divided into four groups: control $(n=6)$, sugammadex $(n=6)$, pregnant $(n=6)$, and pregnant sugammadex $(n=6)$. Ketamine $(50 \mathrm{mg} / \mathrm{kg})$ and xylazine $(10 \mathrm{mg} / \mathrm{kg})$ were administered intraperitoneally to all groups. Saline $(\mathrm{SF})(1 \mathrm{ml} / \mathrm{kg})$ was administered to the control and pregnant groups. Sugammadex was administered to the sugammadex and pregnant sugammadex groups at a dose of $16 \mathrm{mg} / \mathrm{kg}$. Blood samples were collected at $30 \mathrm{~min}$ after SF and sugammadex administration in all rats. The levels of PT, INR, aPTT, fibrinogen and coagulation factors were measured in plasma obtained from blood samples. All animals were sacrificed by cervical dislocation after the procedure.

The mean weights of the rats were significantly higher in the pregnant groups (pregnant and pregnant sugammadex groups) than in the non-pregnant groups (control and sugammadex groups). The mean PT and INR values were significantly lower in the pregnant than non-pregnant groups. No significant differences were observed in any of the parameters evaluated between the sugammadexand SF-administered groups.

Sugammadex administration did not affect routine coagulation tests or the levels of coagulation factors in pregnant rats.
\end{abstract}

Keywords: Sugammadex, pregnancy, rats, blood coagulation tests, blood coagulation factors

\section{Introduction}

Nondepolarizing muscle relaxants are preferred because they are safer during anesthesia, and antagonism of these agents is required when terminating general anesthesia. The undesirable side effects of depolarizing muscle relaxants that do not require antagonism include increases in plasma potassium levels and intraocular pressure (1).

Although a cholinesterase inhibitor can be used as an antagonist, its combined use with a parasympatholytic agent is required to prevent undesirable side effects, such as bradycardia and bronchospasms (2). Sugammadex, which is used clinically to antagonize rocuronium, has clinical advantages such as no muscarinic side effects, no need to combine with an additional agent, and recovery of a moderate-to-deep block without waiting (3). However, sugammadex has been reported to affect coagulation parameters in some studies (3-5).

General anesthesia is the first choice in obstetric cases with impaired coagulation, particularly for cesarean section, and antagonization with sugammadex after rapid sequence induction with rocuronium is an essential part of anesthesia (6-7). However, the effects of sugammadex on coagulation in pregnant women have not been evaluated adequately.

This study investigated the effects of sugammadex administration on the levels of routine coagulation parameters and coagulation factors (FII, FV, FVII, FVIII, FIX, and FX) in pregnant rats.

${ }^{*}$ Corresponding Author: Mehmet Emin Keskin, Van Education and Research Hospital, University of Health Sciences, Depertmant of Anesthesiology and Reanimation, Van, Turkey Edremit, 65100

E-mail: emin6559@hotmail.com,Phone; +90 (553)0716655

ORCID ID: Mehmet Emin Keskin: 0000-0003-1915-175X, Havva Sayhan Kaplan: 0000-0001-7682-2666, Nurçin Gülhas: 0000-00022539-9017, Yasemin Bayram: 0000-0001-6083-5550, Yildiray Basbugan: 0000-0001-5124-7853

Received: 18.11.2020, Accepted: 28.01.2021 


\section{Materials and Methods}

This study was performed in July 2019 at Yuzuncu Yil University Experimental Medicine Application and Research Center with permission of the Yuzuncu Yil University Animal Experts Local Ethics Committee on June 27, 2019 (decision number 2019/06).

Selection of Experimental Animals: In this study, 24 healthy female Wistar albino rats (weight 230-380 $\mathrm{g}$ ), including 12 that were pregnant, were used. The rats that were healthy had not been used in any previous study or exposed to any drugs. The rats were maintained at $20-24^{\circ} \mathrm{C}$ under a 12 -h light/12-h dark photoperiod and were allowed to drink water and eat standard rat food until two $h$ before receiving anesthesia and analgesia.

The Conception of Rats and Detection of Pregnancy: The female rats were divided randomly into two groups of 10 rats each. Two female and one male rat were placed in the same cage for two nights. The male rats were removed, which was considered the first day of pregnancy. The pregnancies of the rats were followed up by daily abdominal examinations until processing (days 19-20 of gestation), and those who did not complete pregnancy were excluded from the study.

Methods: The rats were weighed using precision scales before the procedure. Before administering saline or sugammadex for sedation and analgesia to all rats, $50 \mathrm{mg} / \mathrm{kg}$ ketamine (Ketalar $1 \mathrm{ml}, 50 \mathrm{mg}$, Pfizer, Istanbul, Turkey) and $10 \mathrm{mg} / \mathrm{kg}$ xylazine (Xylazinbio 2\% Biovet, Ivanovie, Czech Republic) were administered intraperitoneally (i.p.), and anesthesia was maintained using ketamine. The rats were randomly divided into four groups $(\mathrm{n}=6)$ and were numbered by marking.

Control group ( $\mathrm{n}=6$ ): $1 \mathrm{ml} / \mathrm{kg} \mathrm{SF}$ administered i.p.

Sugammadex group $(\mathrm{n}=6): 16 \mathrm{mg} / \mathrm{kg}$ sugammadex (Bridion $^{\mathrm{R}} 200 \mathrm{mg} / 2 \mathrm{ml}, \mathrm{MSD}$, North Carolina, USA) administered i.p.

Pregnant group $(\mathrm{n}=6): 1 \mathrm{ml} / \mathrm{kg} \mathrm{SF}$ administered i.p.

Pregnant sugammadex group $(\mathrm{n}=6): 16 \mathrm{mg} / \mathrm{kg}$ sugammadex administered i.p.

Approximately $30 \mathrm{~min}$ after drug or SF administration, a $4 \mathrm{ml}$ blood sample was collected from the heart, and the number of offspring of the pregnant rats was recorded in all groups.

Rat Blood Samples: The blood samples were transferred to coagulation tubes containing 3.2\% sodium citrate. Target parameters were examined at the Van Yuzuncu Yil University Faculty of Medicine Dursun Odabaş Medical Center Microbiology Laboratory. The D-dimer level was measured using the Radiometer AQT90 FLEX immunoassay (Myco Instrumentation Inc. Copenhagen, Denmark) analyzer. The blood samples were centrifuged at 3,000 $\mathrm{rpm}$ for $5 \mathrm{~min}$ in an NF $800 \mathrm{R}$ centrifuge device (Nuve Ankara, Turkey). The plasma samples were placed in Eppendorf tubes in duplicate and stored at $-80^{\circ} \mathrm{C}$ until analysis. PT/INR levels were determined in plasma using the Neoptimal kit (Diagnostica Stago Inc. Asnieres, France). aPTT levels were measured using the Cephascreen kit (Diagnostica Stago Inc. Asnieres, France) and fibrinogen levels using the Liquid Fib kit (Diagnostica Stago Inc. Asnieres, France). FII, FV, FVII, FVIII, FIX, and FX levels were measured using the appropriate Deficient kit (Diagnostica Stago Inc. Asnieres, France) and quantitated using the clotting measurement method in the STA fully automated coagulation device (Diagnostica Stago Inc. Asnieres, France). The normal ranges of the values were $11.5-15.5 \mathrm{~s}$ for PT, $0.5-1.5$ for INR, 25-40 s for aPTT, 200-400 mg/dl for fibrinogen level, and 80-500 $\mu \mathrm{g} / \mathrm{L}$ for D-dimer level.

Euthanasia: The animals were sacrificed by cervical dislocation.

Statistical Analysis: SPSS 23.0 software (SPSS Inc., Chicago, IL, USA) was used for the statistical analysis. All data are presented as means \pm standard deviation (range). A P-value $<0.05$ was considered significant. The Shapiro-Wilk test was used to determine the normality of the data. One-way analysis of variance was used to compare parameters among the experimental groups. Tukey's multiple comparison test was used to determine between-group differences.

\section{Results}

The mean weights of the rats in the pregnant groups (pregnant and pregnant sugammadex groups) were significantly higher than those in the non-pregnant groups (control and sugammadex groups) $(\mathrm{P}<0.05)$ (Table 1).

The mean PT values of the groups are given in Table 2. The mean PT values were significantly lower in the pregnant and pregnant sugammadex groups than in the control and sugammadex groups $(\mathrm{P}<0.05)$ (Table 1). The mean aPT'T values tended to be higher in the groups administered sugammadex than in those administered SF. However, there was no significant difference $(\mathrm{P}>0.05)$ (Table 2). The mean INR values were significantly lower in the pregnant and pregnant sugammadex groups than in the control and sugammadex groups $(\mathrm{P}<0.05)$ (Table 2$)$.

The mean fibrinogen level tended to be lower in the pregnant sugammadex group than that in the 
Table 1. Rat weights [Mean \pm SD (minimum-maximum)]

\begin{tabular}{cccccc}
\hline & $\begin{array}{c}\text { Group C } \\
(\mathrm{n}=6)\end{array}$ & $\begin{array}{c}\text { Group S } \\
(\mathrm{n}=6)\end{array}$ & $\begin{array}{c}\text { Group P } \\
(\mathrm{n}=6)\end{array}$ & $\begin{array}{c}\text { Grpup PS } \\
(\mathrm{n}=6)\end{array}$ & $\mathrm{P}$ \\
\hline Weight & $256,00 \pm 20,00$ & $267,00 \pm 27,00$ & $308,00 \pm 20,00^{*}$ & $300,00 \pm 60,00^{*}$ & 0,036 \\
$(\mathrm{~g})$ & $(230-282)$ & $(234-294)$ & $(278-340)$ & $(238-378)$ & \\
\hline
\end{tabular}

(Group C: Control group, Group S: sugammadex group, Group P: Pregnant Group, Group PS: Pregnant-sugammadex group)

Table 2. Routine coagulation test results of rats [Mean \pm SD (minimum-maximum)]

\begin{tabular}{lccccc}
\hline & $\begin{array}{c}\text { Group C } \\
(\mathrm{n}=6)\end{array}$ & $\begin{array}{c}\text { Group S } \\
(\mathrm{n}=6)\end{array}$ & $\begin{array}{c}\text { Group P } \\
(\mathrm{n}=6)\end{array}$ & $\begin{array}{c}\text { Group PS } \\
(\mathrm{n}=6)\end{array}$ & P \\
\hline PT (sec) & $23,28 \pm 2,51$ & $22,48 \pm 1,88$ & $18,4 \pm 2,10^{*}$ & $19,17 \pm 0,69 *$ & 0,03 \\
& $(21,50-28)$ & $(19,4-24,6)$ & $(16,2-21,8)$ & $(18,2-20,2)$ & \\
aPTT (sec) & $16,43 \pm 3,49$ & $18,15 \pm 1,82$ & $15,70 \pm 1,38$ & $17,53 \pm 3,56$ & 0,227 \\
& $(11,3-19,8)$ & $(14,8-19,6)$ & $(13,4-16,7)$ & $(11,6-21,8)$ & \\
INR & $1,83 \pm 0,21$ & $1,76 \pm 0,16$ & $1,42 \pm 0,17 *$ & $1,49 \pm 0,06^{*}$ & 0,03 \\
& $(1,68-2,22)$ & $(1,50-1,93)$ & $(1,24-1,70)$ & $(1,41-1,57)$ & \\
Fibrinogen & $274,50 \pm 129,4$ & $313,67 \pm 92,74$ & $387,83 \pm 50,85$ & $379,83 \pm 81,93$ & 0,081 \\
(mg/dl) & $(178-529)$ & $(217-475)$ & $(335-475)$ & $(290-510)$ & \\
\hline
\end{tabular}

(Group C: Control group, Group S: sugammadex group, Group P: Pregnant Group, Group PS: Pregnant-sugammadex group)

Table 3. Factor levels of rats [Mean \pm SD (minimum-maximum)]

\begin{tabular}{lccccc}
\hline & $\begin{array}{c}\text { Group C } \\
(\mathrm{n}=6)\end{array}$ & $\begin{array}{c}\text { Group S } \\
(\mathrm{n}=6)\end{array}$ & $\begin{array}{c}\text { Group P } \\
(\mathrm{n}=6)\end{array}$ & $\begin{array}{c}\text { Group PS } \\
(\mathrm{n}=6)\end{array}$ & P \\
\hline FII $(\%)$ & $38,17 \pm 15,27$ & $33,84 \pm 8,26$ & $33,50 \pm 11,98$ & $42,00 \pm 10,16$ & 0,558 \\
& $(22-58)$ & $(23-45)$ & $(25-67)$ & $(25-55)$ & \\
F V $(\%)$ & $240,67 \pm 51,71$ & $244,50 \pm 47,07$ & $197,67 \pm 85,08$ & $292,00 \pm 19,60$ & 0,063 \\
& $(152-300)$ & $(197-300)$ & $(62-300)$ & $(252-300)$ & \\
F VII $(\%)$ & $298,00 \pm 4,00$ & $298,00 \pm 4,90$ & $300,00 \pm 0,00$ & $261,17 \pm 95,12$ & 0,444 \\
& $(290-300)$ & $(288-300)$ & $(300-300)$ & $(67-300)$ & \\
FVIII $(\%)$ & $211,00 \pm 170,10$ & $154,67 \pm 80,69$ & $68,00 \pm 43,73$ & $67,17 \pm 58,19$ & 0,059 \\
& $(38-448)$ & $(23-237)$ & $(19-134)$ & $(13-167)$ & \\
F IX $(\%)$ & $41,50 \pm 19,77$ & $40,50 \pm 15,78$ & $28,50 \pm 20,22$ & $45,67 \pm 25,94$ & 0,53 \\
& $(18-70)$ & $(22-57)$ & $(15-69)$ & $(15-81)$ & \\
F X (\%) & $21,50 \pm 11,99$ & $19,33 \pm 6,44$ & $31,83 \pm 20,52$ & $31,83 \pm 14,62$ & 0,304 \\
& $(11-40)$ & $(11-26)$ & $(13-70)$ & $(11-49)$ & \\
\hline
\end{tabular}

(Group C: Control group, Group S: sugammadex group, Group P: Pregnant Group, Group PS: Pregnant-sugammadex group)

pregnant group. However, there was no significant difference $(\mathrm{P}>0.05)$. (Table 2).

The mean coagulation factor levels in the groups are shown in Table 3. No significant differences in mean FII, FV, FVII, or FIX levels were observed among the groups $(\mathrm{P}>0.05)$ (Table 3). The mean FVIII and FX levels tended to be lower and higher, respectively, in the pregnant groups than in the non-pregnant groups. However, there was no significant difference (P > 0.05). (Table 3).

The mean D-dimer level in all subjects was $80 \mu \mathrm{g} / \mathrm{L}$.

\section{Discussion}

Administration of $16 \mathrm{mg} / \mathrm{kg}$ sugammadex did not affect PT, aPTT, or INR values or the coagulation factor levels in pregnant rats. The increased levels of coagulation factors and decreased levels of natural anticoagulants and fibrinolytic activity induced by the physiological changes during pregnancy increase the possibility of thrombosis (8,9). Although anticoagulants used for prophylaxis of thromboembolism reduce maternal mortality from 
thromboembolic diseases during the postpartum period, they restrict the use of regional anesthesia and emphasize the preference for general anesthesia (10). Sugammadex is frequently used in pregnant women to antagonize muscle relaxation, which is a part of general anesthesia (6,7). Sugammadex affects coagulation in vitro by affecting prothrombin to thrombin conversion via $\mathrm{FXa}$ in the common pathway (11). Therefore, in our study, we evaluated coagulation factor levels. Because the most common surgery performed during pregnancy is cesarean, we used rats in their last trimester of pregnancy (days 1920).

In vivo and in vitro studies have shown that sugammadex has dose-dependent anticoagulant effects in clotting tests (11). Increasing the sugammadex dose prolonged the dilute Russel viper venom time and high phospholipid sensitive aPTT time in an in vitro study (4). De Kamp et al. (12) reported that the PT/INR value was longer after 16 $\mathrm{mg} / \mathrm{kg}$ compared with $4 \mathrm{mg} / \mathrm{kg}$ sugammadex administration to nine healthy volunteers. Sugammadex at doses of 2 and $4 \mathrm{mg} / \mathrm{kg}$ was not associated with increased bleeding in a retrospective study of high-risk patients (11), but new prospective studies are needed to evaluate the effects of high doses of sugammadex $(16 \mathrm{mg} / \mathrm{kg})$. We used 16 $\mathrm{mg} / \mathrm{kg}$, which is the maximum recommended dose in humans, in this study to evaluate the effect of sugammadex on coagulation parameters in pregnant women.

The effect of sugammadex on coagulation parameters is reportedly temporary ( $\leq 30 \mathrm{~min}$ ) (3). Rahe-Meyer et al. (5) evaluated 184 patients who were undergoing joint prosthetic surgery. Treatment with $4 \mathrm{mg} / \mathrm{kg}$ sugammadex resulted in increases in aPTT of 5.5\% after $10 \mathrm{~min}$ and of $0.9 \%$ after $1 \mathrm{~h}$ and in PT/INR of $3 \%$ after 10 min and of $0.9 \%$ after $1 \mathrm{~h}$ compared with neostigmine treatment. De Kamp et al. (12) showed that the increases in PT/INR and aPTT occurred within $30 \mathrm{~min}$ in nine healthy volunteers. In our study, blood samples were obtained $30 \mathrm{~min}$ after drug administration, and the experiment was terminated. We also detected no significant differences in the mean PT/INR values between the groups treated with sugammadex and those treated with SF. Following our study, Taş et al. (13) detected no significant difference in PT/INR in the sugammadex group compared with the neostigmine group in 50 patients scheduled to undergo septoplasty. Another study reported an $11 \%$ increase in PT/INR at $15 \mathrm{~min}$ after administration of sugammadex (12). The time of PT/INR evaluation was 10 min in the study by RaheMeyer et al. and $15 \mathrm{~min}$ in that by De Kam et al. Both times were much shorter than the time at which blood samples were collected in our current study.
Dirkmann et al. (4) demonstrated no significant difference in the fibrinogen level among groups treated with sugammadex alone, sugammadex with rocuronium, rocuronium alone, or saline in an in vitro study of 18 healthy volunteers. Our results support those findings, as we did not detect a significant difference in the fibrinogen level among groups.

In a literature review, we did not identify any study other than that performed by Dirkmann et al. (4), who found no effect of sugammadex on coagulation factor levels. In support of that study, we did not find any significant differences among groups in the mean levels of FII, FV, FVII, or FX, which play a role in the extrinsic and common pathways. In the same study, Dirkmann et al. (4) observed significant decreases in FVIII and FIX levels, which play roles in the intrinsic pathway, in the sugammadex group compared with the other groups. However, in the current study, no significant differences in mean FVIII or FIX levels were observed among the groups. Dirkmann et al. (4) performed an in vitro study, and sugammadex was added to the blood samples to reach a certain final concentration. We think that the discrepancy between our and their results may be due to this difference in methodology.

In our study, the mean PT/INR values were significantly lower in the pregnant than non-pregnant groups. Coagulation factors, such as von Willebrand factor, FVIII, FV, and fibrinogen, increase during pregnancy, whereas natural anticoagulants and fibrinolytic activity decrease (8,9). In our study, coagulation activity was increased in the pregnant compared with the non-pregnant groups.

We believe that the hypercoagulability created by pregnancy may have reduced the effect of $16 \mathrm{mg} / \mathrm{kg}$ sugammadex on coagulation parameters in our study The potential limitations of our study are that sugammadex was administered intraperitoneally instead of intravenously, $>16 \mathrm{mg} / \mathrm{kg}$ doses of sugammadex were not used, blood samples have taken at thirty minutes after drug administration (were not taken earlier or later) and the samples could not studied on ROTEM or TEG devices because were not available in our hospital.

Treatment with $16 \mathrm{mg} / \mathrm{kg}$ sugammadex did not affect coagulation in pregnant rats. Although no significant differences were detected in the coagulation parameters, aPTT was prolonged in both the sugammadex and pregnant sugammadex groups. The number of studies examining the effect of sugammadex on coagulation is insufficient. Thus, there is a need for large-scale studies in pregnant women, including the use of different doses of sugammadex, combination with rocuronium, and evaluation of blood samples at different times. In conclusion, we believe that these results will lead to 
studies on the effect of sugammadex on coagulation in pregnant women.

\section{References}

1. Naguib M, Lien C.A. Pharmacology of muscle relaxant and their antagonists. In: Miller RD (ed.) Miller's Anesthesia. 7th edition. Philadelphia: Churchill Livingstone Elsevier 2010; 859-911.

2. Belgin A. The Inhibitors of Cholinesterase (Anticholinesterases). Turkiye Klinikleri J Int Med Sci 2005; 1: 47-57.

3. EMA: helping doctors help patients [Internet]. Amsterdam: European Medicines Agency; C1995-2019 [cited 2019 June 17]. Available from: https://www.ema.europa.eu/en/documents/pro duct-information/bridion-epar-productinformation_en.pdf

4. Dirkmann D, Britten MW, Pauling H, Weidle J, Volbracht L, Görlinger K, et al. Anticoagulant Effect of Sugammadex: Just an In Vitro Artifact. Anesthesiology 2016; 124: 1277-1285.

5. Rahe-Meyer N, Fennema H, Schulman S, Klimscha W, Przemeck M, Blobner M et al. Effect of reversal of neuromuscular blockade with sugammadex versus usual care on bleeding risk in a randomized study of surgical patients. Anesthesiology 2014; 121 : 969-977.

6. D'Angelo R. Anaesthesia-related maternal mortality: a pat on the back or call to arms. Anesthesiology 2007; 106: 1082-1084.
7. Hawkins JL, Chang J, Palmer SK, Gibbs CP, Callaghan WM. Anaesthesia-related maternal mortality in the United States: 1979-2002. Obstetric Gynaecol 2011; 117: 69-74.

8. Hellgren M. Hemostasis in normal pregnancy and puerperium. Semin Thromb Hemost 2003; 26: 244-247.

9. Stirling Y, Woolf L, North WR, Seghatchian MJ, Meade TW. Haemostasis in normal pregnancy. Thromb Haemostas 1984; 52: 176-182.

10. Sucak G,Sucak A. Pregnancy and Hypercoagulability. Turkiye Klinikleri J Int Med Sci 2001; 1: 40-47.

11. Raft J, Guerci P, Harter V, Fuchs-Buder T, Meistelman C. Biological evaluation of the effect of sugammadex on hemostasis and bleeding. Korean journal of anesthesiology 2015; 68: 17-21.

12. De Kam PJ, Grobara P, Prohn M, Höppener F, Kluft C, Burggraaf J et al. Effects of sugammadex on activated partial thromboplastin time and prothrombin time in healthy subjects. International journal of clinical pharmacology and therapeutics 2014; 52: 227-236.

13. Taş N, Korkmaz H., Yağan Ö, Korkmaz M. Effect of sugammadex on postoperative bleeding and coagulation parameters after septoplasty: a randomized prospective study. Medical science monitor: international medical journal of experimental and clinical research 2015; 21: 23822386. 